\title{
Emerging synthesis themes from the study of social-ecological systems of a tropical city
}

\author{
Tischa A. Muñoz-Erickson ${ }^{1}$, Ariel E. Lugo $^{1}$ and Braulio Quintero $^{2}$
}

\begin{abstract}
The synthesis of the contributions in this special issue about the tropical city of San Juan has resulted in five themes. First, the city is subject to multiple vulnerabilities, but socioeconomic factors and education level affect the perception of citizens to those vulnerabilities, even in the face of imminent threat. Second, in light of the social-ecological conditions of the city, how its citizens and institutions deal with knowledge to respond to vulnerabilities becomes critical to the adaptive capacity of the city. Third, the relationship between socioeconomic factors and green cover, which in 2002 covered $42 \%$ of the city, is not what has been reported for other temperate zone cities. In San Juan, neighborhoods with households of high socioeconomic level were not necessarily associated with greater green cover. However, in adjacent neighborhoods within the densely populated zones of the city, households of high socioeconomic level did preserve green cover better than households in lower socioeconomic-level neighborhoods. Fourth, tropical conditions such as climate may explain some of the unique aspects of the social-ecological system of San Juan. The most obvious is the exuberance of tropical biota in the city that not only forms novel species assemblages but also provides many ecological services, including food production for up to $60 \%$ of the members of particular neighborhoods. Ecosystem resilience is particularly high in aquatic and terrestrial ecological systems in San Juan. Fifth, it appears that the emergence of novel systems in the city represent adaptive responses to the social end ecological conditions in the city. We conclude that the study of a tropical city provides contrast to the prevailing literature on temperate and boreal cities and expands the suite of behaviors of urban social-ecological systems, thus advancing the dialogue on the functioning of cities in light of environmental change.
\end{abstract}

Key Words: adaptive capacity; green and blue infrastructure; information flows; novel ecosystems; social-ecological systems; tropical cities; vulnerability

\section{INTRODUCTION}

The initial ecological studies of the Río Piedras River Watershed (RPRW) led to multiple surprises because ecologists had underestimated ecological persistence in anthropogenic environments and the adaptability of organisms to cities (Lugo 2010). This motivated a recognition of synergistic interaction between the biota of cities and humans that many have argued results in a social-ecological system (SES), supported by both natural and anthropogenic forces (Redman et al. 2004, Kinzig et al. 2005, Pickett et al. 2011). This synergy between natural and anthropogenic forces justifies a social-ecological approach to understand the sources of vulnerability and sustainability for the city. However, unlike the extensive studies of temperate cities, SES studies in the urban tropics are underexplored.

We summarize five synthesis themes that emerged from the socialecological studies of the RPRW in the San Juan Metro Area of Puerto Rico. Although this serves as an introduction of many of the articles included in the special issue, our synthesis covers more broadly the results generated by an interdisciplinary study of the vulnerability and sustainability of the city by the San Juan Urban Long-Term Research Area (ULTRA). San Juan ULTRA began in 2010 as an exploratory inquiry on the condition of the city because of concerns over the vulnerability of ecological and social systems to increasing stresses and risks, e.g., flood hazards and other effects of climate change. The program has now evolved into a long-term investigation of how tropical urban SESs function and adapt to present and future environmental changes. The long-term objective of the San Juan ULTRA program is therefore to use the SES approach to evaluate the state of the current urban system, examine how management interventions affect the system, and anticipate potential development trajectories given the system's capacity, policy goals, and external factors. We refer to the growing literature of vulnerability, resilience, and sustainability science as the link between understanding SES function and the long-term viability of the system (e.g., Turner et al. 2003, Eakin and Luers 2006). As suggested by Nelson et al. (2007) and Miller et al. (2010), our exploration of the study of urban SESs seeks to bridge epistemologically distinct traditions from ecological and social sciences by capitalizing on the complementary approaches of vulnerability and resilience frameworks.

Vulnerability is a system property that evaluates the condition of the SES that is to be affected by a disturbance (Brooks et al. 2005, Downing et al. 2005). The extent to which actors, populations, or systems are likely to be affected by a hazard or disturbance event depends critically on context, exposure to the hazard, the type of hazard in question, and the capacity to cope and adapt (Cutter et al. 2003, Turner et al. 2003). In our study of San Juan, we employ physical, historical-geographical, and actor-based approaches to understand the socio-political factors and environmental linkages that underpin the vulnerability of the city (McLaughlin and Dietz 2008). However, traditional vulnerability approaches often focus only on system conditions and not on the long-term outcomes of these processes (Eakin and Luers 2006, Miller et al. 2010). Thus, we complement this analysis with examination of the feedbacks of social and ecological systems at multiple spatial and temporal scales that the ecological resilience framework has contributed (Holling 1973, Walker et al. 2004).

${ }^{1}$ USDA Forest Service International Institute of Tropical Forestry, Puerto Rico, ${ }^{2}$ State University of New York, College of Environmental Science and Forestry 
Fig. 1. A heuristic model of the social-ecological system within the Río Piedras River Watershed. The left side of the box representing the watershed contains the ecological systems of the city, identified as green infrastructure. The right side of the diagram contains the social systems and gray infrastructure. Outside circles represent driving external forces to the watershed. Bulleted symbol represents systems with photosynthetic capacity, while hexagons represent systems that only consume energy through respiration or combustion. Tanks represent the accumulation of water, mass, waste, or land. Lines with arrows represent the flux of energy or materials. Most fluxes are unidirectional following the arrowhead. Other fluxes, like the tidal water exchange, atmospheric air ventilating the system, inflow and outflow of vehicles and people, or water flow through pipes can be bidirectional. Not all fluxes are illustrated but they are implied for the purpose of simplifying the diagram. For example, government influence and several external drivers, like policies, dollar fluxes, or information fluxes, connect with most sectors of the city but are left unconnected for simplicity. The same is true for the effects of hurricanes, earthquakes and warming. Color in the diagram is for aesthetic purposes. The text contains more details.

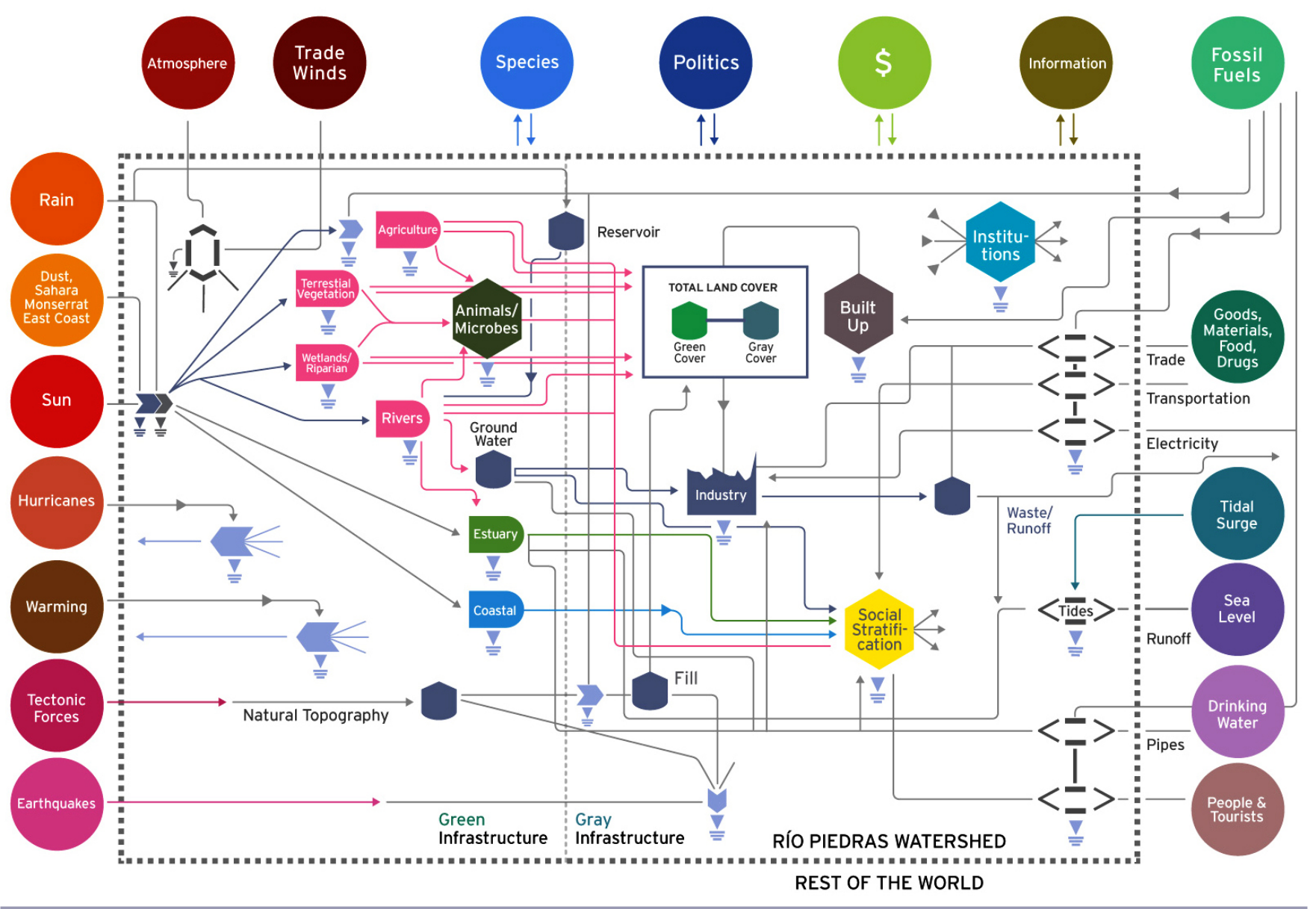

Resiliency also helps us think about how SES dynamics respond in times of crises and build adaptive capacity to transform to a different state (Adger 2000, Folke et al. 2002, Folke 2006). The last component of our framework is sustainability, which provides the link between system condition, policy goals, and future development trajectories. More importantly, sustainability adds a normative, i.e., value-based, dimension to studying the SES. Sustainability recognizes that there are multiple socially desirable states and that these are defined and maintained by political values, institutional structures, and cultural factors (Norton 2005 , Leach et al. 2010). Therefore, sustainability involves the identification of desirable, yet sometimes conflicting, development trajectories and the ability of the SES to move toward any one of them.
Because the details of the concepts, methodologies, and practices we undertook as part of this overall conceptual framework are too extensive to discuss within the space limitations of this synthesis, we discuss these elsewhere in conceptual papers (Lugo et al., in press; T. A. Muñoz-Erickson, A. E. Lugo, E. MelendezAckerman, L. E. Santiago-Acevedo, J. Seguinot-Barbosa, P. Méndez-Lázaro, M. Hall, B. Quintero, A. Ramírez, D. GarciaMontiel, J. R. Ortíz-Zayas, C. M. Concepción, R. Gilmore Pontius, Jr., O. Ramos-González, R. Santiago-Bartolomei, J. C. Verdejo-Ortiz, M. Luz Cruz-Torres, J. Giusti, J. Vallejo, L. Cray, B. McDowell, J. Zimmerman, V. Cuadrado-Landrau, and M. Figueroa, unpublished manuscript) and in the empirical studies presented in this special issue. We present a synthesis of the findings from the first, exploratory phase of this long-term 
research program. Our synthesis is organized in five parts consistent with the five synthesis themes, followed by a conclusion and discussion of future research.

\section{MULTIPLE SOURCES OF VULNERABILITIES}

We modeled the SES of the RPRW as a joint effort among San Juan ULTRA participants (Fig. 1). The objective of the heuristic model is to assist our research group in developing a common conceptual understanding of the RPRW as a integrated system. As our knowledge evolves and the group learns more about the city, the model will be modified in the future. For now, the model has allowed us to explore the most important external forces that influence social-ecological subsystems of the RPRW (Fig. 1, circles) as well as the main subsystem components (Fig. 1, various symbols with labels) and interactions (Fig. 1, one-way and twoway bulleted symbols). We see these driving forces as potential sources of vulnerability to the urban system because these external drivers either support the functions of the city or have the potential of disturbing the city.

The external driving forces of the system in Figure 1 are organized such that the natural ones are to the left and the anthropogenic ones are to the right, with the exception of the sea level and tidal surges, which are located on the bottom right of the diagram. There are 11 natural and 7 anthropogenic driving forces in the diagram. However, most of these exchanges as well as the anthropogenic activities within the watershed are facilitated by fossil fuel imports, which appear to be a major driving force of the watershed. Nonetheless, these driving forces do not equally affect all social groups in the city, nor do people experience any positive effects or vulnerabilities resulting from these driving forces in the same way. For instance, as consistent with other studies of climate change vulnerability (e.g., Adger 1999, 2006), J. Seguinot-Barbosa (unpublished manuscript) found that the less privileged groups of the RPRW are more vulnerable to effects of climate change, e.g., sea-level rise, flooding, and salinity, than groups of higher socioeconomic status. It is important then to also understand who are the potential winners and losers as the city adapts to changing social-ecological conditions. Next, we discuss how important fossil fuels and food imports are to the city and how they can become major sources of vulnerability to which the city must adapt or else face an uncertain future.

We illustrate the importance of an external driver to the functioning of the city with an analysis of the dependency of the city on fossil fuels and food supply. The trends for these two factors appear to head in different directions. For example, the level of agricultural production in Puerto Rico and the importance of the agricultural sector to the economy plummeted over the last 50 years (Fig. 2), and there is no sign of recovery. Therefore, San Juan, like all of Puerto Rico, is vulnerable to a food crisis should food imports be impeded for any reason. The cost of fossil fuels is one exogenous driving force that can affect the whole economy of the island including the food supply and cost. Puerto Rico imports fossil fuels to generate its electricity and operate vehicles and machinery. Fossil fuel imports have increased over time irrespective of the cost of a barrel of oil. However, in contrast to the tendency with agriculture, the economy in general has become more energy efficient and now uses less oil to generate gross national product (Fig. 3). Although this trend is a positive for the economy, the availability of fossil fuels remains a vulnerability because practically all the economic activity requires a continuous supply of imported energy if it is to function at the levels at which it has in the past. Given the threat of peak oil, discussed widely by scientists (http://www.theoildrum.com/), Puerto Rico stands at a critical juncture in its development because any solution for a sustainable future must deal with energy and food vulnerabilities.

Fig. 2. The history of decline of agricultural activity in Puerto Rico and of its contribution to the Island's gross national product. This is based on official records of the Puerto Rico Agriculture Department.

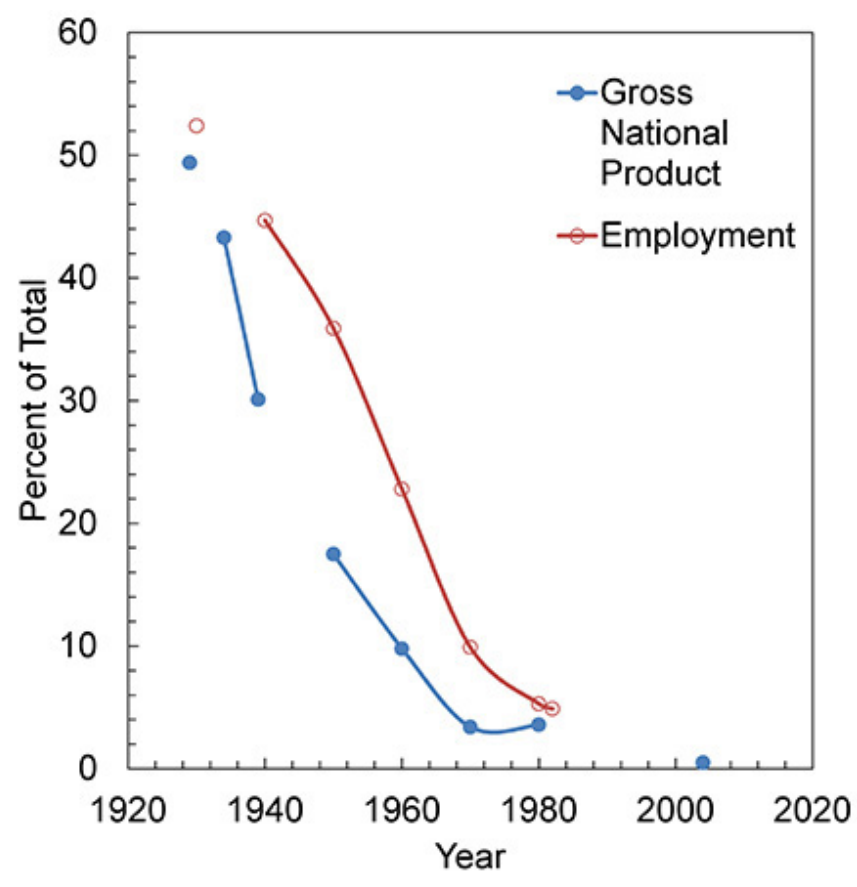

Fig. 3. The increase in energy use efficiency by the economy of Puerto Rico is illustrated by the increasing economic output in spite of a leveling of the energy importation.

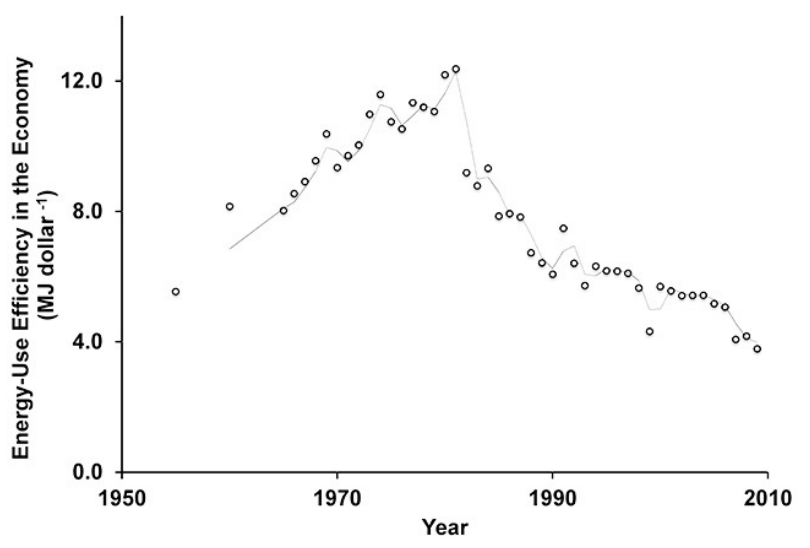




\section{HOW CITY NETWORKS THINK}

A central component to analyzing the vulnerability of SESs is understanding the socio-political dynamics and actor interactions that internally condition levels of risk and adaptability (Nelson et al. 2007, McLaughlin and Dietz 2008). We focus on the collective perceptions and social expectations of the urban environment as produced from the networked interaction among city actors, i.e., individuals, groups, and organizations, and their various knowledge, ideas, and worldviews. Doing so is what we refer to as how city networks think (Muñoz-Erickson 2012).

As noted previously, Seguinot-Barbosa (unpublished manuscript) studied the vulnerability to flooding and other elements of climate change of various neighborhoods in San Juan and found that not all the communities in the city are vulnerable to the same elements of climate change, nor are they exposed to the same levels of vulnerability. However, the level of real and perceived vulnerability varies according to the socioeconomic and educational status of the communities. Seguinot-Barbosa found that some communities clearly exposed to severe flooding and potential sea-level rise perceived themselves as not vulnerable to these risks, and that this happened in poorly educated sectors of the society, which contrasted to the more realistic perceptions of the educated sectors. Santiago-Bartolomei's (2012) study of residents' perceptions across the watershed confirms this misconception, with half of the residents surveyed not perceiving risks to flooding even though they were located within flooding zone areas. Many people are not aware of the relationship of changes in the type of land cover in the watershed with flooding risk. This suggests that information flow and effectiveness of information dissemination to the public are having an effect on how communities of the RPRW think and perceive their environment and its hazards. Extensive research on risk perceptions, however, has shown that various other factors, including affective, cognitive, values, e.g., environmental and political, and attitudes, also shape risk perceptions (Leiserowitz 2006, Slimack and Dietz 2006, Larson et al. 2011).

At the level of governance, the flow of information in San Juan was fragmented and ineffective at facilitating knowledge sharing among multiple organizations, including state and local agencies, nongovernmental organizations (NGOs), academic institutions, and community groups. Fragmentation and sectoral policies in city environmental governance have been observed in other cities. In Paris, for instance, antagonistic relationships between the city, region, and state over environmental governance were evident (Blanc et al. 2013). In 2009 in San Juan, Muñoz-Erickson (2014a) mapped the intra-urban information networks for land-use and green area governance and found that information flow was dominated by a few central organizations of the state that have little information exchange with local organizations, including the Municipality of San Juan and NGOs. Power asymmetries among different ways of knowing and lack of vertical information exchange between top and bottom institutions may explain why the state and the city had different visions for the future of the city of San Juan (Muñoz-Erickson 2014b). The Economically Sustainable City vision of the state, for instance, was supported by a technocratic knowledge system that relied on state-level statistics and economic models of development. The Livable City vision developed through the Municipality's Office of Planning and Territorial Ordinance was supported by both professional and local expertise of the city's physical and social conditions. Knowledge about local ecological functions in the city, although increased in amount and diversity through scientific and NGO efforts, was also fragmented and thus limited the ability of bottom-up governance processes and their visions to acquire more power in the network, e.g., Ecologically Sustainable vision. Thus, the extent to which new ideas and initiatives for the development of the city could have a significant influence on governance and adaptive capacity was limited by a fragmented network, power asymmetries in knowledge systems, and lack of critical analysis and discourse of the multiple pathways that were being forged for the city.

\section{INTERACTION BETWEEN PEOPLE AND GREEN INFRASTRUCTURE}

Melendez-Ackerman et al. (2014) found that socioeconomic factors operating in different sectors of the city had different outcomes in relation to the prevalence of green area cover. The relationship between green cover and humans, however, is not straightforward. As we discuss subsequently, the studies of Melendez-Ackerman et al. and those cited later show that socioeconomic factors in some cases favor but in others threaten green area cover, however, not in the way observed for temperate cities.

The vegetation of San Juan covered about $42 \%$ of the land (Ramos-González 2014) in 2002 and grows rapidly, consistent with the moist and warm maritime climate of the city (Lugo et al. 2011). About half of the green areas of the city are under direct control of households in the form of backyards and gardens (Ramos-González 2014). Vila-Ruiz et al. (2014) found 383 woody plant species on 18.7 ha of yards inventoried. All of these plant species were selected and maintained by people in their yards. In return, a large portion of the population obtains food from these patios as well as other ecological services. For example, Garcia-Montiel et al. (2014) found that in neighborhoods where residential density was low with large areas of vegetative cover, more than $60 \%$ of residents consumed food items cultivated in their yards. In the densely urbanized parts of the city, up to $36 \%$ of residents consumed items from their yards. Moreover, those neighborhoods in rural upper watershed environments discharge sanitary waters directly to the environment, which means that, in part, water quality for residents in the lower portions of the watershed depends on the pollution removal effectiveness of soil and vegetation in the upper watershed.

Ramos-Santiago et al. (2014) studied three neighborhoods and found that those at a lower socioeconomic scale, i.e., Puerto Nuevo and Caparra Terrace, respectively lost at a minimum $60 \%$ and $55 \%$ of private green area and $85 \%$ and $79 \%$ of their public planting strip areas, whereas University Gardens with a higher socioeconomic level lost $36 \%$ of private green areas and $23 \%$ of public planting strip areas. All three communities had been planned communities that were subject to dramatic land cover changes as they aged, but one maintained more green infrastructure than the others, commensurate with socioeconomic level. Other social processes also affected the results (Table 1) further demonstrating how green infrastructure presence in a city is dependent on political economic processes (Heynen 2006). 
Table 1. Social processes affecting the green infrastructure of San Juan, Puerto Rico (Ramos-Santiago et al. 2014).

\begin{abstract}
- Residential to commercial land-use conversions along arterial and principal local avenues, mostly due to national and metropolitan-scale economic growth and development.
\end{abstract}

- The simultaneous aging of housing stock and demographic/ socioeconomic change to produce increments in density, rentals, and housing units at the residential core of the two lower-income neighborhoods, result in green cover trends associated to neighborhood decline process. In the upper income neighborhood the increment in gross density and housing units was accommodated in multistory condominium typologies with minimal effects on green areas and imperceptible to the overall neighborhood suburban character.

- The progressive shift in transportation mode from bus transit to massive individual car ownership in the two lowerincome neighborhoods. Because of specific physical-spatial limitations in the two lower-income neighborhoods the increment of automobile ownership results in higher diminishment of private and public green areas and green cover.

- Cultural preferences and unforeseen resident spatial needs produce smaller aggregate footprint expansions that contribute to overall green area loss in time.

Even some of the largest blocks of public forested vegetation in the city owe their presence to humans, who allowed their establishment after total deforestation for agricultural or urban use. In one case, the San Patricio State Forest, neighborhood mobilization and activism saved the forest from development and had it designated as a protected area. Ironically, the forest developed after abandonment of a military base. Most green and blue city areas contain combinations of native and introduced species (Lugo et al. 2005, Román-Nunci et al. 2005, Suárez et al. 2005, Ramírez et al. 2012), again highlighting the closeness of the interaction between people and green infrastructure. Clearly, studies of the ecology of vegetation need to consider the history of site development and the social and ecological factors that mediate the presence, structure, species composition, and functioning of plant communities. Similarly, the socioeconomic studies of neighborhoods must take into consideration the ecological services, both direct and indirect, that these neighborhoods derive from the green infrastructure.

\section{SOME THINGS ARE DIFFERENT IN THE TROPICS}

Tropical latitudes are known for their warm climate and continuous growing seasons for vegetation in those areas lacking dry seasons. Among the high diversity of life zone conditions in the tropics, defined empirically by Holdridge (1967), the lowland moist life zones are the most productive (Brown and Lugo 1982) because they have sufficient moisture to overcome the drying power of the atmosphere, but not excessive moisture to cause anaerobic soil conditions attributable to excessive saturation. Different aspects of the climate of San Juan are described by others (Méndez-Lázaro et al. 2014a; P. Méndez-Lázaro, O. Martínez-Sánchez, R. Méndez-Tejeda, E. Rodríguez, and E. Morales, unpublished manuscript) and show that the normal temperatures in the city are moderate and the rainfall abundant, the extreme events that are described notwithstanding. These conditions lead to high rates of vegetation productivity and growth, which underpins the resiliency of green areas to natural and anthropogenic disturbances (Lugo et al. 2005, Duryea et al. 2007) while also explaining some of the observations discussed subsequently relating socioeconomic factors and green infrastructure in the city. The tropical climate of San Juan is also an asset for tourism (Méndez-Lázaro et al. 2014b).

Several studies in this volume obtained results that were unexpected based on similar studies in temperate zones. For example, in San Juan, neighborhoods in the southern portion of the city with a lower socioeconomic position have more access to green infrastructure than ones with higher levels of socioeconomic status (Santiago et al. 2014), an opposite trend to what has been observed in cities like Phoenix (Kinzig et al. 2005) and Baltimore (Grove et al. 2006). However, their health does not improve by the presence of green infrastructure (Hernández 2012). The explanation for these apparent paradoxes has to do with the tropical climate and culture of the people. Low-income people in the tropics tend to grow their own food in backyards, and the tropical climate supports rapid vegetation growth without a winter reduction in productivity. However, they live in the more rural sectors of the city with lower accessibility to health facilities. Neighborhoods with households of higher income level are located in more urban settings with smaller backyards but greater accessibility to supermarkets (Garcia-Montiel et al. 2014) and health care facilities.

Tropical conditions also allow for a higher biodiversity of organisms in cities, such that the notion of homogenization so much highlighted in temperate zones (Lososová et al. 2012) does not occur in San Juan. As an example, a constructed 1-ha forest within a San Juan neighborhood contains 37 tree species, i.e., 9 native and 28 introduced, all planted by people in the neighborhood (Román-Nunci et al. 2005). Although introduced species dominate green areas in San Juan, i.e., importance value of $67 \%$ (Lugo and Brandeis 2005), they do not homogenize communities. Instead, they form diverse novel forests throughout the city (Lugo et al. 2011). Abelleira Martínez (2010) examined the homogenization potential of Spathodea campanulata, the most common and most invasive tree species in Puerto Rico, and could not find evidence of homogenization under a variety of substrate conditions. The tropical city has a high level of biodiversity and, contrary to temperate cities, does not appear to be on a path toward homogenization of the biota. The study of Vázquez-Plass (2008) is instructive because the bird fauna steadily increased in abundance and species richness from wilderness to $80 \%$ built cover in an urban area of Puerto Rico. Lososová et al. (2012) raised the issue of longevity as a factor that contributed to homogenization of central Europe's urban floras. They argued that recent species arrivals do not cause homogenization, but after 
centuries of presence in the urban environment expand to all possible available environments and then do contribute to homogenization. Their analysis spanned 5 centuries, a time much longer than available for neotropical cities. However, Lugo (2004) showed that under tropical conditions succession is faster and monocultures of introduced species tend to diversify as succession proceeds.

The issue of homogenization involves a sequential and selective process because it is argued that human activity is resulting in the loss of endemic and local native species and the expansion of introduced common weedy species, such that environments become more alike and less unique in terms of species composition (McKinney and Lockwood 2001). We don't question the expansion of introduced species into anthropogenic environments or the displacement of native species in these environments. However, our experience shows that in our tropical conditions human activity leads to novel species combinations, i.e., a new mix of native and introduced species, that can be as diverse and unique as the ones displaced. Humans contribute by selecting those species that they use or like, but processes of naturalization, self-organization, and succession also contribute to the development of new species combinations that function in the city as novel ecological systems and deliver ecological services.

Melendez-Ackerman et al. (2014) found that yard characteristics are highly related to household demographic profiles as opposed to household income status, a finding that also contrasts with those of temperate cities. They attributed the lack of a household income effect to the contextual differences in the natural and economic environments across cities, implying the need for holistic analysis of social-ecological phenomena, taking into consideration both the social and the ecological peculiarities of urban systems. As an example of how ecological peculiarities affect the social-ecological interactions associated with yard maintenance, MelendezAckerman et al. (2014) discuss how the moist conditions of San Juan result in significantly less treated water demand for yard maintenance than in temperate cities where evapotranspiration conditions are less favorable for plant growth, resulting in higher water consumption for yard maintenance.

\section{NOVELTY IS THE PATH TO ADAPTABILITY?}

We don't think it is an accident that the city is dominated by novel ecological systems where introduced species can predominate over native ones (Lugo et al. 2011, Ramírez et al. 2012). In fact, we believe the opposite, that novelty of species composition is the response to the physical and socially challenging and unpredictable landscape of the city. San Juan has a heat island effect (Velazquez-Lozada et al. 2006, Murphy et al. 2011), is subject to sea-level rise (Lugo et al. 2004), has filled $23 \%$ of its mangrove environments (Webb and Gómez-Gómez 1998), and has located vital infrastructure in these filled lands (Lugo et al. 2011). Moreover, the whole municipality was once deforested, and a majority of its land used for agricultural production (Lugo et al. 2011). Thus, the $42 \%$ of land cover today occupied by green cover must support vegetation on degraded soils or fill material, and plants must grow in altered climatic conditions and subject to inconsistent human intervention in the form of multiple disturbances. Streams and lagoons in San Juan have had their channels (Phillips and Scatena 2013) or bathymetry (Lugo et al. 2011) altered and their water polluted with a variety of pollutants of diverse origin (Ramírez et al. 2012, 2014). Such conditions are novel for native aquatic species, but surprisingly, the natural succession in both terrestrial and aquatic systems has led to high biological diversity and high productivity, as well as to mixed species systems with new combinations of native and introduced species. In short, the novel anthropogenic conditions of the city have produced novel species compositions of organisms inhabiting terrestrial and aquatic environments.

A social parallel to this novelty we are observing is that alternative visions and initiatives are emerging across the city in response to a centralized state planning system that has been dominated historically by economic and technocratic ways of seeing the city (Muñoz-Erickson 2014b). Community and nongovernmental efforts that are facilitated by a diversity of visions, social networks, and ways of knowing the system, e.g., local knowledge, social indicators, or science, are increasingly common in the city's political landscape.

Figure 4 illustrates our inference of how novelty facilitates the path to adaptability in cities. Each urban subsystem, i.e., forest, stream, yard, and neighborhood, has a common structural makeup as shown on top of the figure. This common framework includes natural and anthropogenic energy sources, i.e., illustrated with solar and fossil fuel energy sources, respectively, and natural and anthropogenic components such as vegetation and urban structures or institutions, respectively. These components interact with multiple positive and negative feedbacks that contribute to their behavior as integrated systems. The relative importance of the natural or anthropogenic components within each subsystem depends on the balance of external inputs and their interactions with system components. In fact, a city is a place where many alternate solutions to environmental or social conditions are tested, and this is illustrated in the figure as a choice generator of subsystems, each representing alternative approaches to dealing with environmental and social conditions. Not all will prove successful over time, and many will drop out as viable alternatives to the city's ever-changing conditions. Constrained inputs to the city, cultural dynamics, and political-economic choice will favor adaptable solutions shown to the right of the diagram in Figure 4.

Fig. 4. Diagram of a basic social-ecological unit (top) and how in a dynamic urban system selection based on multiple such units can lead to learning and adaptation. The diagram is based on the adaptation to flooding in the city. Multiple alternative solutions are generated but few prove adaptable. The text contains details.

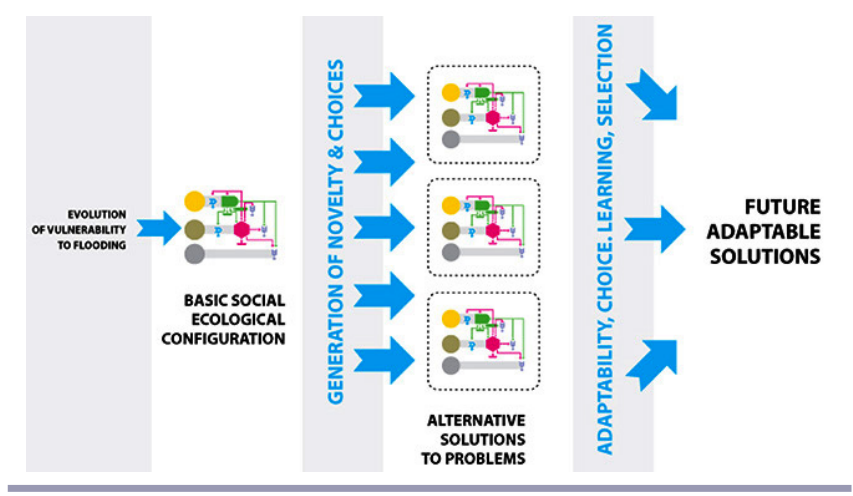


The dramatic changes that have taken place in San Juan, listed previously, act as a selective force for those combinations of natural and anthropogenic subsystems that can cope with the novel conditions. When we examine the composition of these emerging subsystems, we find novel ecological and social systems as has been shown for the urban forests, the stream biota, and in the contrasting visions of the city. We believe that adaptability to uncertainty required novelty of response and are now exploring this relationship with the conceptual model shown in Figure 4. When challenged by socioeconomic conditions, political realities, and changing physical environments, the best-adapted subsystems will prevail as proposed by the ecological and social systems coevolution proposal of Gual and Norgaard (2010).

We recognize that this conceptual model brings to the forefront the epistemological tensions that have long been at the core of understanding human-environment interactions; see, for instance, Aguirre (2007) and Miller et al. (2010) for recent reviews of the divergence and convergence of disciplinary traditions. Our intention is not to make grand, positivistic notions about the coevolution of SESs. Rather, we propose this model as a tool for experimentation about the resilience and adaptive outcomes of different representations of the system and potential future trajectories given internal and external forces. We recognize that novelty and adaptability in cities is partly a product of the distribution of social power relations that select some ecological or social components of the urban landscape over others, e.g., species composition, social groups, and ideas (Swyngedouw and Heynen 2003, Heynen 2006). In other words, these city attributes do not neutrally emerge from the feedbacks of ecological and social systems free from cultural or individual influences, as may be implied by organismic metaphors in the social sciences, e.g., Chicago school understanding of urban systems. Nor does selection takes place only through natural forces, as evolutionary perspectives in the natural sciences would suggest. We agree with Gual and Norgaard (2010) that the role of power relationships is a priority research topic to further our understanding of SES coevolution, and thus we seek to explore this as part of our model in the future.

\section{CONCLUSION}

We presented a synthesis of SES studies for a tropical urban system. The papers in this special issue and the synthesis themes that have emerged represent a first step in a long-term interdisciplinary program that seeks to understand the vulnerability and sustainability of the city of San Juan and tropical urban systems in general. Thus, social-ecological understanding of the city of San Juan is just emerging. The works presented in this special issue only scratch the surface of how this city shapes and is shaped by its interaction with its ecological system.

What does the case of San Juan contribute to the study of cities as SESs? The San Juan case study in this special issue provides a social-ecological exploration of a tropical city in the moist tropics. The moist tropics sensu Holdridge (1967) is the life zone where 19 of the 21 capitals of Latin American countries occur. Thus, research in San Juan has applicability to other cities in the moist tropics. However, our research in the moist tropics also has a more fundamental implication to the understanding of the urban SES. With the notable exception of cities like New York, Baltimore,
Phoenix, and Cape Town, South Africa, where urban ecological and urban social-ecological knowledge is well advanced, in much of the urban literature from temperate and boreal zones, the ecological components are under-represented and the built-up cover draws most of the attention. Moreover, natural systems in temperate and boreal latitudes are less productive than in the tropics because their growing season is interrupted by frost. In San Juan, the presence of green and blue cover is not only high as we have shown, but it is also productive and has high biological diversity. This effect of climate on the biota of San Juan has two important implications for the overall goal of understanding urban SESs. First, San Juan is at the end of a global urban gradient that spans from a dominance of impervious surfaces with little green and blue cover to one where green and blue cover can match impervious surfaces. Thus, the prominent role of the natural component can be appreciated in cities such as San Juan, where a proportion of that green and blue cover is a product of the human-environmental interactions in the urban system. Second, the rapid response of this urban ecosystem to disturbances highlights the role of green and blue infrastructure in the mitigation of vulnerabilities that result from the built-up component of city.

San Juan also presents a unique challenge relative to the wellstudied temperate cities, and some moist tropic cities, because the political, economic, and physical infrastructure of this 500-yearold city developed through a mix of old, e.g., Spanish city planning influences, and new, e.g., U.S. suburban pattern, tendencies in urban planning and governance. Also, mismatches between the ecological and the social systems have been historically shaped by top-down centralized institutional structures. However, bottom-up responses and practices, e.g., residential yard management, are emerging as a source of opportunity for green infrastructure establishment and for building the adaptive capacity of the city as a whole. Thus, San Juan is an ideal city to explore urban social-ecological interactions when both sides of the equation, i.e., the social and the ecological, are vibrant and robust. Although there is still much uncharted territory to understand how this SES works and what will affect its ability to endure over time, through this special issue we have laid the intellectual and methodological foundations to navigate it.

Responses to this article can be read online at: http://www.ecologyandsociety.org/issues/responses. $\mathrm{php} / 6385$

\section{Acknowledgments:}

This paper builds on the work of the scientists and partners collaborating in the San Juan ULTRA. This work was supported by the National Science Foundation (NSF) under grant number 0948507 (Urban Long-Term Research Area Exploratory) and the USDA Forest Service. Any opinions, findings, and conclusions or recommendations expressed in this material are those of the authors and do not necessarily reflect the views of the NSF or the USDA Forest Service. 


\section{LITERATURE CITED}

Abelleira-Martínez, O. J. 2010. Invasion by native tree species prevents biotic homogenization in novel forests of Puerto Rico. Plant Ecology 211:49-64.

Adger, W. N. 1999. Social vulnerability to climate change and extremes in coastal Vietnam. World Development 27:249-269. http://dx.doi.org/10.1016/S0305-750X(98)00136-3

Adger, W. N. 2000. Social and ecological resilience: are they related? Progress in Human Geography 24(3):347-364. http://dx. doi.org/10.1191/030913200701540465

Adger, W. N. 2006. Vulnerability. Global Environmental Change 16:268-281. http://dx.doi.org/10.1016/j.gloenvcha.2006.02.006

Aguirre, B. E. 2007. Dialectics of vulnerability and resilience. Georgetown Journal of Poverty Law and Policy XIV(1):39-59.

Blanc, N., T. LaMarche, A. Sourdril, S. Glatron, A. Rankovic, and D. Haugustaine. 2013. Governance of urban natures: Paris case study. Paper presented at the Urban Sustainability Research Coordination Network, Urban Governance Workshop, 7 October 2013, Baltimore, Maryland, USA.

Brooks, N., W. N. Adger, and P. M. Kelly. 2005. The determinants of vulnerability and adaptive capacity at the national level and the implications for adaptation. Global Environmental Change 15:151-163. http://dx.doi.org/10.1016/j.gloenvcha.2004.12.006

Brown, S., and A. E. Lugo. 1982. The storage and production of organic matter in tropical forests and their role in the global carbon cycle. Biotropica 14:161-187. http://dx.doi.org/10.2307/2388024

Cutter, S. L., B. J. Boruff, and W. L. Shirley. 2003. Social vulnerability to environmental hazards. Social Science Quarterly 84(2):242-261. http://dx.doi.org/10.1111/1540-6237.8402002

Downing, T. E., J. Aers, J. Soussan, O. Barthelemy, S. Bharwani, J. Hinkel, C. Ionescu, R. J. T. Klein, L. J. Mata, N. Matin, S. Moss, D. Purkey, and G. Ziervogel. 2005. Integrating social vulnerability into water management. NeWater Working Paper No. 5., Stockholm Environment Institute, Stockholm, Sweden.

Duryea, M. L., E. Kampf, R. C. Littell, and C. D. RodríguezPedraza. 2007. Hurricanes and the urban forest: II. Effects on tropical and subtropical tree species. Arboriculture \& Urban Forestry 33:98-112.

Eakin, H., and A. L. Luers. 2006. Assessing the vulnerability of social-environmental systems. Annual Review of Environment and Resources 31:365-394. http://dx.doi.org/10.1146/annurev. energy.30.050504.144352

Folke, C. 2006. Resilience: the emergence of a perspective for social-ecological systems analyses. Global Environmental Change 16:253-267. http://dx.doi.org/10.1016/j.gloenvcha.2006.04.002

Folke, C., S. Carpenter, T. Elmqvist, L. Gunderson, C. S. Holling, B. Walker, J. Bengtsson, F. Berkes, J. Colding, K. Danell, M. Falkenmark, L. Gordon, R. Kasperson, N. Kautsky, A. Kinzig, S. Levin, K. Mäler, F. Moberg, L. Ohlsson, P. Olsson, E. Ostrom, W. Reid, J. Rockström, H. Savenije, and U. Svedin. 2002. Resilience and sustainable development: building adaptive capacity in a world of transformations. Scientific Background Paper on Resilience for the process of the World Summit on Sustainable development on behalf of the Environmental Advisory Council to the Swedish Government. Environmental Advisory Council, Ministry of the Environment, Stockholm, Sweden.

Garcia-Montiel, D., J. C. Verdejo-Ortiz, R. Santiago-Bartolomei, C. P. Vila-Ruiz, L. Santiago, and E. Melendez-Ackerman. 2014. Food sources and accessibility and waste disposal patterns across an urban tropical watershed: implications for the flow of materials and energy. Ecology and Society 19(1): 37. http://dx.doi. org/10.5751/ES-06118-190137

Grove, J. M., A. R. Troy, J. P. M. O’Neil-Dunne, W. R. Burch, Jr., M. L. Cadenasso, and S. T. A. Pickett. 2006. Characterization of households and its implications for the vegetation of urban ecosystems. Ecosystems 9:578-597. http://dx.doi.org/10.1007/ s10021-006-0116-Z

Gual, M. A., and R. B. Norgaard. 2010. Bridging ecological and social systems coevolution: a review and proposal. Ecological Economics 69:707-717. http://dx.doi.org/10.1016/j.ecolecon.2008.07.020

Hernández, R. 2012. Recreation and health at the Río Piedras River Watershed. University of Puerto Rico, Medical Science Campus, San Juan, Puerto Rica.

Heynen, N. 2006. Green urban political ecologies: toward a better understanding of inner-city environmental change. Environment and Planning A 38:499-516. http://dx.doi.org/10.1068/a37365

Holdridge, L. R. 1967. Life zone ecology. Tropical Science Center, San José, Costa Rica.

Holling, C. S. 1973. Resilience and stability of ecological systems. Annual Review of Ecological Systems 4:1-23. http://dx.doi. org/10.1146/annurev.es.04.110173.000245

Kinzig, A. P., P. Warren, C. Martin, D. Hope, and M. Katti. 2005. The effects of human socioeconomic status and cultural characteristics on urban patterns of biodiversity. Ecology and Society 10(1): 23. [online] URL: http://www.ecologyandsociety. org/vol10/iss1/art23/

Larson, K. L., A. Wutich, D. White, T. A. Muñoz-Erickson, and S. Harlan. 2011. Multifaceted perspectives of water risks and policies: a cultural domains approach in a southwestern city. Research in Human Ecology 18(1):75-87.

Leach, M., I. Scoones, and A. Stirling. 2010. Dynamic sustainabilities: technology, environment, social justice. Earthscan, London, UK.

Leiserowitz, A. 2006. Climate change risk perception and policy preferences: the role of affect, imagery, and values. Climate Change 77:45-72. http://dx.doi.org/10.1007/s10584-006-9059-9

Lososová, Z., M. Chytrý, L. Tichý, J. Danihelka, K. Fajmon, O. Hájek, K. Kintrová, D. Láníková, Z. Otýpková, and V. Řehořek. 2012. Biotic homogenization of Central European urban floras depends on residence time of alien species and habitat types. Biological Conservation 145:179-184. http://dx.doi.org/10.1016/j. biocon.2011.11.003

Lugo, A. E. 2004. The outcome of alien tree invasions in Puerto Rico. Frontiers in Ecology and the Environment 2:265-273. http:// dx.doi.org/10.1890/1540-9295(2004)002[0265:TOOATI]2.0.CO;2

Lugo, A. E. 2010. Let's not forget the biodiversity of the cities. 
Biotropica 42(5):576-577. http://dx.doi.org/10.1111/ j.1744-7429.2010.00673.x

Lugo, A. E., and T. A. Brandeis. 2005. New mix of alien and native species coexist in Puerto Rico's landscapes. Pages 484-509 in D. Burslem, M. Pinard, and S. Hartley, editors. Biotic interactions in the tropics. Their role in the maintenance of species diversity. Cambridge University Press, Cambridge, UK. http://dx. doi.org/10.1017/CBO9780511541971.021

Lugo, A. E., C. M. Concepción, L. E. Santiago-Acevedo, T. A. Muñoz-Erickson, J. C. Verdejo-Ortiz, R. Santiago-Bartolomei, J. Forero-Montaña, C. J. Nytch, H. Manrique, and W. ColónCortés. In press. In search of an adaptive social-ecological approach to understanding a tropical city. Acta Científica.

Lugo, A. E., A. Ramos-Álvarez, A. Mercado, D. L. L. Feliciano, G. Cintrón, L. Márquez-D’Acunti, R. Chaparro, J. FernándezPorto, S. J. Peisch, and J. Rivera-Santana. 2004. Cartilla de la zona marítimo-terrestre. Acta Científica 18:1-148.

Lugo, A. E., O. M. Ramos González, and C. Rodríguez Pedraza. 2011. The Rio Piedras watershed and its surrounding environment. Publication FS-980, U.S. Forest Service Washington, D.C., USA.

Lugo, A. E., E. Román-Nunci, M. Quiñones, H. Marcano-Vega, and I. Vicéns. 2005. El bosque estatal del nuevo milenio antes y después del huracán Georges. Acta Científica 19:83-105.

McKinney, M. L., and J. L. Lockwood. 2001. Biotic homogenization: a sequential and selective process. Pages 1-17 in

J. L. Lockwood and M. L. McKinney, editors. Biotic homogenization. Kluwer Academic/Plenum, New York, New York, USA. http://dx.doi.org/10.1007/978-1-4615-1261-5 1

McLaughlin, P., and T. Dietz. 2008. Structure, agency and environment: toward an integrated perspective on vulnerability. Global Environmental Change 18:99-111. http://dx.doi.org/10.1016/ j.gloenvcha.2007.05.003

Melendez-Ackerman, E. J., R. Santiago-Bartolomei, C. P. VilaRuiz, L. E. Santiago, D. Garcia-Montiel, J. C. Verdejo-Ortiz, H. Manrique-Hernández, and E. Hernandez-Calo. 2014. Socioeconomic drivers of yard sustainable practices in a tropical city. Ecology and Society 19(3): 20. http://dx.doi.org/10.5751/ES-06563-190320

Méndez-Lázaro, P. A., A. Nieves-Santiago, and J. MirandaBermúdez. 2014a. Trends in total rainfall, heavy rain events, and number of dry days in San Juan, Puerto Rico, 1955-2009. Ecology and Society 19(2): 50. http://dx.doi.org/10.5751/ES-06464-190250

Méndez-Lázaro, P. A., J. J. Terrasa-Soler, C. Torres-Peña, P. Guzmán-González, S. Rodríguez, M. Alemán, and T. Seguinot. $2014 b$. Tourism and climate conditions in San Juan, Puerto Rico, 2000-2010. Ecology and Society 19(2): 11. http://dx.doi. org/10.5751/ES-06380-190211

Miller, F., H. Osbahr, E. Boyd, F. Thomalla, S. Bharwani, G. Ziervogel, B. Walker, J. Birkmann, S. Van der Leeuw, J. Rockström, J. Hinkel, T. Downing, C. Folke, and D. Nelson. 2010. Resilience and vulnerability: complementary or conflicting concepts? Ecology and Society 15(3): 11. [online] URL: http:// www.ecologyandsociety.org/vol15/iss3/art11/

Muñoz-Erickson, T. A. 2012. How cities think: knowledge-action systems for urban sustainability. Dissertation. Arizona State
University, Tempe, Arizona, USA.

Muñoz-Erickson, T. A. 2014a. Co-production of knowledgeaction systems in urban sustainable governance: the KASA approach. Environmental Science \& Policy 37:182-191.

Muñoz-Erickson, T. A. 2014b. Multiple pathways to sustainability in the city: the case of San Juan, Puerto Rico. Ecology and Society19(3): 2. http://dx.doi.org/10.5751/ES-06457-190302

Murphy, D. J., M. H. Hall, C. A. S. Hall, G. M. Heisler, S. V. Stehman, and C. Anselmi-Molina. 2011. The relationship between land cover and the urban heat island in northeastern Puerto Rico. International Journal of Climatology 31 (8):1222-1239. http://dx.doi.org/10.1002/joc.2145

Nelson, D. R., W. N. Adger, and K. Brown. 2007. Adaptation to environmental change: contributions of a resilience framework. Annual Review of Environment and Resources 32:395-419. http:// dx.doi.org/10.1146/annurev.energy.32.051807.090348

Norton, B. G. 2005. Sustainability: a philosophy of adaptive ecosystem management. University of Chicago Press, Chicago, Illinois, USA. http://dx.doi.org/10.7208/chicago/9780226595221.001.0001

Phillips, C. B., and F. N. Scatena. 2013. Reduced channel morphological response to urbanization in a flood-dominated humid tropical environment. Earth Surface Processes and Landforms 38:970-982. http://dx.doi.org/10.1002/esp.3345

Pickett, S. T. A., M. L. Cadenasso, J. M. Grove, C. G. Boone, P. M. Groffman, E. Irwin, S. S. Kaushal, V. Marshall, B. P. McGrath, C. H. Nilon, R. V. Pouyat, K. Szlavecz, A. Troy, and P. Warren. 2011. Urban ecological systems: scientific foundations and a decade of progress. Journal of Environmental Management 92:331-362. http://dx.doi.org/10.1016/j.jenvman.2010.08.022

Ramírez, A., A. Engman, K. G. Rosas, O. Perez-Reyes, and D. M. Martinó Cardona. 2012. Urban impacts on tropical island streams: some key aspects influencing ecosystem response. Urban Ecosystems 15:315-325. http://dx.doi.org/10.1007/s11252-011-0214-3

Ramírez, A., K. G. Rosas, A. E. Lugo, and O. M. RamosGonzález. 2014. Spatio-temporal variation in stream water chemistry in a tropical urban watershed. Ecology and Society 19 (2): 45. http://dx.doi.org/10.5751/ES-06481-190245

Ramos-González, O. M. 2014. The green areas of San Juan, Puerto Rico. Ecology and Society 19(3): 21. http://dx.doi. org/10.5751/ES-06598-190321

Ramos-Santiago, L. E., L. Villanueva-Cubero, L. E. SantiagoAcevedo, and Y. N. Rodriguez-Melendez. 2014. Green area loss in San Juan's inner-ring suburban neighborhoods: a multidisciplinary approach to analyzing green/gray area dynamics. Ecology and Society 19(2): 4. http://dx.doi.org/10.5751/ ES-06219-190204

Redman, C. L., J. M. Grove, and L. H. Kuby. 2004. Integrating social science into the Long-Term Ecological Research (LTER) Network: social dimensions of ecological change and ecological dimensions of social change. Ecosystems 7:161-171. http://dx.doi. org/10.1007/s10021-003-0215-Z

Román-Nunci, E., H. Marcano-Vega, I. Vicéns, G. Bortolamedi, and A. E. Lugo. 2005. El bosque del Parque Central de la 
urbanización El Paraíso: estructura, composición de especies y crecimiento de árboles. Acta Científica 19:73-81.

Santiago, L. E., J. C. Verdejo Ortiz, R. Santiago-Bartolomei, E. J. Melendez-Ackerman, and D. C. Garcia-Montiel. 2014. Uneven access and underuse of ecological amenities in urban parks of the Río Piedras watershed. Ecology and Society 19(1): 26. http://dx. doi.org/10.5751/ES-06180-190126

Santiago-Bartolomei, R. 2012. Riparian and pluvial restoration of the Rio Piedras and its tributaries: a collaborative framework in the management of ecosystem services. Thesis. Graduate School of Planning, University of Puerto Rico, Río Piedras, Puerto Rico.

Slimak, M. W., and T. Dietz. 2006. Personal values, beliefs and ecological risk perception. Risk Analysis 26:1689-1705. http://dx. doi.org/10.1111/j.1539-6924.2006.00832.x

Suárez, A., I. Vicéns, and A. E. Lugo. 2005. Composición de especies y estructura del bosque kárstico de San Patricio, Guaynabo, Puerto Rico. Acta Científica 19:7-22.

Swyngedouw, E., and N. C. Heynen. 2003. Urban political ecology, justice and the politics of scale. Antipode 35(5):898-918. http://dx.doi.org/10.1111/j.1467-8330.2003.00364.X

Turner, B. L., II, R. E. Kasperson, P. A. Matson, J. J. McCarthy, R. W. Corell, L. Christensen, N. Eckley, J. X. Kasperson, A. Luers, M. L. Martello, C. Polsky, A. Pulsipher, and A. Schiller. 2003. A framework for vulnerability analysis in sustainability science. Proceedings of the National Academy of Sciences of the United States of America 100(14):8074-8079. http://dx.doi.org/10.1073/ pnas. 1231335100

Vázquez-Plass, E. O. 2008. Avian distribution along a gradient of urbanization in Puerto Rico. Dissertation. University of Puerto Rico, Río Piedras, Puerto Rico.

Velazquez-Lozada, A., J. Gonzalez, and A. Winter. 2006. Urban heat island effect analysis for San Juan, Puerto Rico. Atmospheric Environment 40:1731-1741. http://dx.doi.org/10.1016/j. atmosenv.2005.09.074

Vila-Ruiz, C. P., E. Melendez-Ackerman, R. SantiagoBartolomei, D. Garcia-Montiel, L. Lastra, C. E. Figuerola, and J. Fumero-Caban. 2014. Plant species richness and abundance in residential yards across a tropical watershed: implications for urban sustainability. Ecology and Society 19(3): 22. http://dx.doi. org/10.5751/ES-06164-190322

Walker, B., C. S. Holling, S. R. Carpenter, and A. Kinzig. 2004. Resilience, adaptability and transformability in social-ecological systems. Ecology and Society 9(2): 5. [online] URL: http://www. ecologyandsociety.org/vo19/iss2/art5/

Webb, R. M. T., and F. Gómez-Gómez. 1998. Synoptic survey of water quality and bottom sediments, San Juan Bay estuary system, Puerto Rico, December 1994-July 1995. Water Resources Investigations Report 97-4144, U.S. Geological Survey, San Juan, Puerto Rico. 